ÉGYPTE

monde arabe

\section{Égypte/Monde arabe}

10 | 2013

Les élections de la révolution (2011-2012)

\title{
Les stratégies de campagne des partis politiques au niveau local : étude comparée de trois circonscriptions
}

\section{Clément Steuer}

\section{(2) OpenEdition}

\section{Journals}

Édition électronique

URL : https://journals.openedition.org/ema/3156

DOI : 10.4000/ema.3156

ISSN : 2090-7273

Éditeur

CEDEJ - Centre d'études et de documentation économiques juridiques et sociales

Édition imprimée

Pagination : 155-185

ISBN : 978-2-905838-81-0

ISSN : $1110-5097$

Référence électronique

Clément Steuer, «Les stratégies de campagne des partis politiques au niveau local : étude comparée de trois circonscriptions », Égypte/Monde arabe [En ligne], 10 | 2013, mis en ligne le 10 février 2014, consulté le 07 juillet 2022. URL : http://journals.openedition.org/ema/3156 ; DOI : https://doi.org/ 10.4000/ema.3156

Ce document a été généré automatiquement le 7 juillet 2022.

Tous droits réservés 


\title{
Les stratégies de campagne des partis politiques au niveau local : étude comparée de trois circonscriptions
}

\author{
Clément Steuer
}

Lors des élections législatives de 2011-2012, les partis égyptiens ont pu - pour la première fois - remplir trois des fonctions qui leur sont habituellement dévolues dans les systèmes démocratiques: l'agrégation des intérêts (à travers la rédaction des programmes électoraux), la sélection des candidats, et la mobilisation des électeurs ${ }^{1}$. Ils ont ainsi joué un rôle central dans ces élections, à tel point que la Haute Cour constitutionnelle, considérant que la loi électorale avait avantagé les partis au détriment des candidats indépendants, a prononcé un jugement entraînant la dissolution de l'Assemblée du peuple. Et en effet, sur 498 députés élus dans cette assemblée, seuls 22 étaient des indépendants ${ }^{2}$. Cette domination sans partage des partis politiques au niveau national ne doit cependant pas masquer la diversité des situations locales. C'est en effet localement que les échéances électorales jouent le rôle le plus crucial dans la construction des organisations partisanes ${ }^{3}$. Or, la nature et la quantité des différentes ressources à la disposition d'un parti donné peuvent grandement varier d'une circonscription à l'autre. Par ailleurs l'usage fait de ces ressources n'est pas forcément identique en fonction du contexte local. Dans cet article, nous nous fonderons sur une comparaison effectuée entre trois circonscriptions égyptiennes élisant leurs représentants à l'Assemblée du peuple pour mettre en lumière l'influence de deux variables exogènes sur la stratégie locale des organisations partisanes ${ }^{4}$ : le degré d'incertitude pesant sur l'élection, et l'importance relative des différentes circonscriptions dans les médias nationaux. 


\section{Un niveau d'incertitude tendanciellement décroissant}

2 Les élections législatives égyptiennes de 2011-2012 ont ceci de particulier que, pour la première fois depuis la fin de l'expérience libérale, il n'était pas possible de savoir avec certitude, en amont du scrutin, quelle serait l'orientation majoritaire du futur parlement élu ${ }^{5}$. Cette incertitude portait également à la fois sur les règles juridiques ${ }^{6}$, les conditions dans lesquelles allait s'exercer l'acte de vote, la composition du corps électoral, le rôle de l'Assemblée du peuple et la durée de son mandat. Concernant d'abord les règles juridiques, la loi électorale avait fait l'objet d'âpres négociations entre le pouvoir militaire et les forces politiques. Elle a été amendée à plusieurs reprises, rendant même nécessaire une révision de la déclaration constitutionnelle ${ }^{7}$. De nombreux points avaient été laissés à l'appréciation du haut comité électoral ${ }^{8}$, et ont fait l'objet d'informations changeantes et parfois contradictoires dans la presse, mais également de rumeurs récurrentes. L'attribution des sièges se fera-t-elle au plus fort reste ou à la plus forte moyenne? (Ce sera au final au plus fort reste) Peut-on se porter candidat à la fois à l'Assemblée du peuple et à l'Assemblée consultative ${ }^{9}$ ? (Il s'avérera que non) L'abstention sera-t-elle sanctionnée par une amende ? (Oui, mais cette mesure n'a pas été appliquée) Cette incertitude juridique est chose habituelle dans l'histoire électorale égyptienne, et elle affecte aussi bien la stratégie des candidats (avec des phénomènes d'asymétrie dans l'accès aux informations) que le comportement des électeurs (l'existence d'une sanction financière pour les abstentionnistes constitue une incitation au vote pour les catégories les plus démunies de la population), mais aussi le travail de tous les acteurs contrôlant le bon déroulement du scrutin ${ }^{10}$.

3 De son côté, l'incertitude quant au contexte dans lequel s'exerce l'acte électoral porte avant tout sur le degré de violence et de fraudes auquel s'attendre durant ces élections. Ces deux instruments faisaient en effet partie de l'arsenal de l'ancien régime. Au cours des deux dernières décennies, violences et fraudes semblaient s'être "privatisées " ${ }^{11}$, dans le sens où elles étaient moins organisées par l'État que par les candidats euxmêmes, mobilisant leurs clientèles ou achetant les services de voyous (les fameux baltagiyya) pour dissuader les électeurs de se rendre aux bureaux de vote dans les quartiers réputés leur être hostiles. De la même manière, les fraudes de ces dernières années étaient en grande partie organisées par les candidats eux-mêmes, notamment à travers l'achat de voix, mais parfois aussi par le vol et la destruction d'urnes. De ce fait, la chute des dirigeants du régime et la dissolution du parti national démocratique (PND) ne garantissaient pas à elles seules la fin de ces pratiques ni même leur diminution. La mobilisation de l'armée, de la police et de la justice, ainsi que la présence de nombreux observateurs nationaux ou internationaux, mandatés par les ONG et les candidats, a finalement permis une réduction spectaculaire des pratiques caractéristiques de l'ancien régime, et notamment des violences physiques. L'incertitude entourant cette échéance électorale a également joué ici un rôle pacificateur, en privant les acteurs coutumiers de ces pratiques du sentiment d'impunité qui les habitait jusqu'alors. Ce dénouement ne doit cependant pas occulter le fait qu'avant le premier tour de scrutin, le niveau de violence et de fraude à attendre de ces élections demeurait une grande inconnue.

4 L'incertitude caractéristique de ce scrutin portait également sur l'étendue et la composition du corps électoral, puisqu'il était impossible d'anticiper tant le taux global de participation que celui des différentes catégories sociales. Jusqu'alors, les élections 
égyptiennes mobilisaient surtout les catégories les plus défavorisées, cible prioritaire des agents électoraux chargés d'acheter des voix pour le compte des candidats fortunés ${ }^{12}$. À la veille du scrutin, personne n'était en mesure de prévoir le niveau de participation des classes moyennes, d'autant que plusieurs mouvements révolutionnaires avaient appelé au boycott des urnes suite aux événements de la rue Muhammad Mahmûd ${ }^{13}$. Enfin, l'incertitude portait sur le futur parlement lui-même. Du fait de l'absence de précédents et des lacunes du recensement, les instituts de sondage se trouvaient en effet dans l'impossibilité de constituer des échantillons représentatifs, et leurs approximations reflétaient surtout la notoriété des différents partis en lice. Bien qu'annoncé en tête des sondages, le parti de la Liberté et de la Justice (PLJ) ${ }^{14}$ n'en était pas moins sous-estimé dans les différentes enquêtes d'opinion, mais moins que la coalition salafiste, à laquelle les sondeurs n'accordaient pas $10 \%$ des intentions de vote. Inversement, les partis libéraux du Wafd (annoncé deuxième) et des Égyptiens libres étaient surestimés par ces mêmes instituts. S'il était ainsi impossible, du moins avant la première phase du scrutin, de se représenter la composition du futur parlement, son rôle et la durée de son mandat faisaient également l'objet de diverses spéculations. Sa nature constituante était ainsi diversement appréciée, certains candidats affirmant à leurs électeurs que son rôle se limiterait à la rédaction de la Constitution, à l'issue de laquelle il serait dissous. Cependant, le gouvernement avait publié quelques semaines avant le premier tour de scrutin un «Document constitutionnel » prévoyant que seul un cinquième des membres de la future constituante serait nommé par les députés, les $80 \%$ restant devant être désignés par le conseil supérieur des forces armées (CSFA). Ce document ayant suscité des manifestations de masse et le renvoi du gouvernement, le rôle exact du parlement dans le processus de rédaction de la Constitution demeurait l'objet d'un rapport de force à l'issue encore incertaine alors même que les électeurs se rendaient aux urnes pour l'élire. Du fait de cette situation extrêmement tendue, l'incertitude pesait même sur la tenue des élections aux dates annoncées. La plupart des observateurs pariaient en effet sur un report des échéances, jusqu'à ce que celles-ci soient finalement solennellement confirmées par le haut comité électoral, en présence de membres du CSFA, quelques jours à peine avant le commencement de la première étape.

5 Néanmoins, du fait de l'organisation des élections en trois phases successives ${ }^{15}$, cette incertitude se réduisit progressivement. Suite à la tenue des élections dans la première zone, les règles du jeu se sont précisées, les comportements admis se sont distingués de ceux qui étaient absolument proscrits ou simplement tolérés, le corps électoral s'est dessiné, et il est devenu possible de faire des projections sur la composition de la future assemblée. Lorsque la dernière phase a commencé, la domination des islamistes au sein du parlement était un fait acquis, et la justice avait déjà eu l'occasion de prononcer l'invalidité du scrutin dans certaines circonscriptions, rendant ainsi effective la distinction entre pratiques légales et illégales dans le cadre de la nouvelle législation. Cette diminution de l'incertitude entourant le scrutin au cours des trois phases successives des élections est due tant à la circulation des informations via les différents médias qu'à l'expérience cumulée des divers acteurs participant à l'organisation de ces élections : ainsi, les juges surveillant les bureaux de vote ont participé à chacune des trois phases, et de nombreux observateurs et journalistes ont également circulé au cours de l'ensemble du processus. Les candidats eux-mêmes ont pu profiter de cette expérience, en tout cas ceux appartenant à des partis implantés nationalement, car ces 
derniers mobilisaient une partie de leurs cadres et militants pour participer successivement à la campagne dans trois zones différentes.

6 Mais si l'incertitude se réduit ainsi progressivement, elle ne disparait pas pour autant, ne serait-ce que parce que la question de l'étendue des pouvoirs constituants du parlement n'a pas encore reçu de réponse définitive. Néanmoins, en suivant le déroulement des élections dans trois circonscriptions votant successivement, il devient possible de mettre en lumière les effets de cette incertitude sur le comportement des acteurs concernés. Il apparaît ainsi progressivement que la violence électorale est en très net recul par rapport aux élections des années 2000. Par ailleurs, les taux de participation et les résultats obtenus dans les premières circonscriptions à voter permettent de se faire une idée plus nette des rapports de force, ce qui influe sur le positionnement des partis en lice. Enfin, la baisse progressive de l'incertitude conduit à une certaine normalisation des pratiques électorales. Ainsi, alors que lors du premier tour de la première étape, tous les partis et candidats font ouvertement campagne à l'entrée même des bureaux de vote, cette pratique se réduit considérablement par la suite. Les grandes organisations (surtout les Frères et les salafistes) se concentrent alors sur les bureaux des quartiers les plus peuplés. Lorsque des observateurs ou des représentants des autorités signalent à des militants que leur activité est illégale, ils font mine de le découvrir et de s'excuser, puis recommencent une fois que la personne qui les a réprimandés a le dos tourné. D'autres adoptent des techniques plus discrètes pour éviter les rappels à l'ordre, tel ce balayeur poussant sa brouette dans les rues de Tanta, faisant surgir dans sa main gauche une poignée d'autocollants aux couleurs du parti de la Réforme et du Développement lorsqu'il passe devant un bureau de vote, et les distribuant aux personnes croisant sa route. Ces manœuvres dilatoires montrent toutefois qu'une pratique encore admise par tous le 28 novembre 2011 a été grandement délégitimée en quelques semaines à peine. Certaines exceptions à la règle semblent néanmoins encore couramment admises. Ainsi, dans le village de Mahallat Minûf, dans la circonscription de Gharbiyya, un candidat local faisait ouvertement campagne à la porte même de sa maison, à quelques mètres du bureau de vote, avec sa famille et ses proches. Alors qu'une observatrice déplorait cet état de fait devant un homme du village qui lui demandait si elle avait constaté des irrégularités, celui-ci lui a répondu : «Ah mais ce n'est pas pareil : lui, il est d'ici ! » ${ }^{16}$.

\section{Présentation des trois circonscriptions étudiées}

7 L'enquête de terrain a pris pour objet trois circonscriptions votant successivement: Qasr Al-Nîl, dans le centre-ville du Caire (28 novembre - 6 décembre), Suez, au sud du canal (14-22 décembre), et la première circonscription de Gharbiyya, dans le delta du Nil (3-11 janvier). Outre l'échelonnement dans le temps du processus électoral, ces trois circonscriptions se distinguent nettement quant au traitement médiatique dont elles ont respectivement bénéficié ${ }^{17}$. Ainsi, les luttes électorales se déroulant dans la circonscription de Qasr Al-Nîl, au cœur de la capitale, sont traditionnellement très médiatisées. Au cours des dernières élections, cette tendance a encore été accentuée du fait que cette circonscription abrite la place Tahrir, ainsi que la rue Muhammad Mahmûd, où des affrontements meurtriers ont opposé plusieurs jours durant policiers et manifestants au cours des deux semaines précédant le premier tour des élections. Il en résulte que les principaux candidats ont été très présents dans les médias nationaux 
au cours de la campagne, et beaucoup moins dans les rues. De son côté, la ville de Suez, du fait de son rôle de symbole national (au moins depuis l'occupation israélienne de 1967) et révolutionnaire (les affrontements de janvier 2011 y ont été particulièrement meurtrier $\left.\mathrm{s}^{18}\right)$, a attiré l'attention des médias, tant nationaux qu'étrangers ${ }^{19}$ durant les élections législatives. Cet intérêt pour Suez, sans être comparable avec la situation prévalant à Qasr Al-Nîl, a attiré dans la ville plusieurs leaders nationaux de premier plan. Durant les quinze jours que j'y ai passés, j'ai ainsi pu assister à un meeting de Abû Al-Ilâ Mâdî et 'Isâm Sultân, les dirigeants du Wasat venus soutenir leurs candidats locaux, à une conférence de Ayman Nûr, de passage à Suez pour inaugurer les nouveaux locaux du Ghad Al-Thawra et soutenir ses candidats, et enfin à un discours de 'Abd AlMun im Abûl-Futûh ${ }^{20}$, en campagne pour les élections présidentielles de mai-juin 2012. Enfin, comparée aux deux précédentes, la première circonscription de Gharbiyya (Tanta, Kafr Al-Zayât, Bassiûn et Qutûr) intéresse relativement peu les journalistes. C'est en effet la ville ouvrière de Mahalla, dans la deuxième circonscription du gouvernorat, qui joue le rôle de symbole révolutionnaire dans cette région, tandis que le gouvernorat voisin de Minûfiyya, d'où est originaire la famille de Moubarak ainsi que plusieurs caciques de l'ancien régime, est présenté comme un bastion contrerévolutionnaire.

8 Cette différence de traitement médiatique a d'ailleurs des répercussions sur les conditions de l'enquête. Ainsi, à Qasr Al-Nîl, l'ensemble des candidats a adopté une attitude d'évitement à l'égard de l'enquêteur. Contactés par téléphone ou dans la rue durant leurs bains de foule, ils lui ont demandé de les rappeler pour ensuite filtrer ses appels, ou bien ont donné des rendez-vous jamais honorés. Extrêmement sollicités par les journalistes, ces candidats n'ont en effet pas de temps à consacrer à un chercheur qui ne travaille pas dans l'immédiateté. Surtout, dans un contexte extrêmement tendu où des affrontements meurtriers opposent la police à des manifestants réclamant la chute du régime militaire, les candidats les plus exposés médiatiquement sont à la merci du moindre faux pas. En conséquence, ils sont enclins à voir dans un enquêteur étranger une source potentielle d'ennuis, d'autant que les plus hautes autorités de l'État, et une partie des médias, interprètent alors les événements comme le résultat de menées déstabilisatrices fomentées par l'étranger pour diviser l'Égypte. À Suez, où les candidats sont moins dépendants de leur image dans les médias nationaux, et où les élections se déroulent alors que le calme est revenu place Tahrir, la plupart des candidats se laissent approcher facilement, seuls les salafistes et les fulûl ${ }^{21}$ mettant en œuvre les habituelles stratégies d'évitement à l'égard de l'enquêteur. Enfin, à Gharbiyya, les candidats et militants de tous les courants ont manifesté une attitude de relative ouverture à mon endroit, y compris les favoris du scrutin ${ }^{22}$. 
Figure 1 : Le mur dressé par l'armée rue Muhammad Mahmûd quelques jours avant le début du premier tour, dans le but de mettre fin aux affrontements, isole la place Tahrir du quartier de 'Abdîn, coupant la circonscription de Qasr Al-Nîl en son milieu (21 janvier 2012)

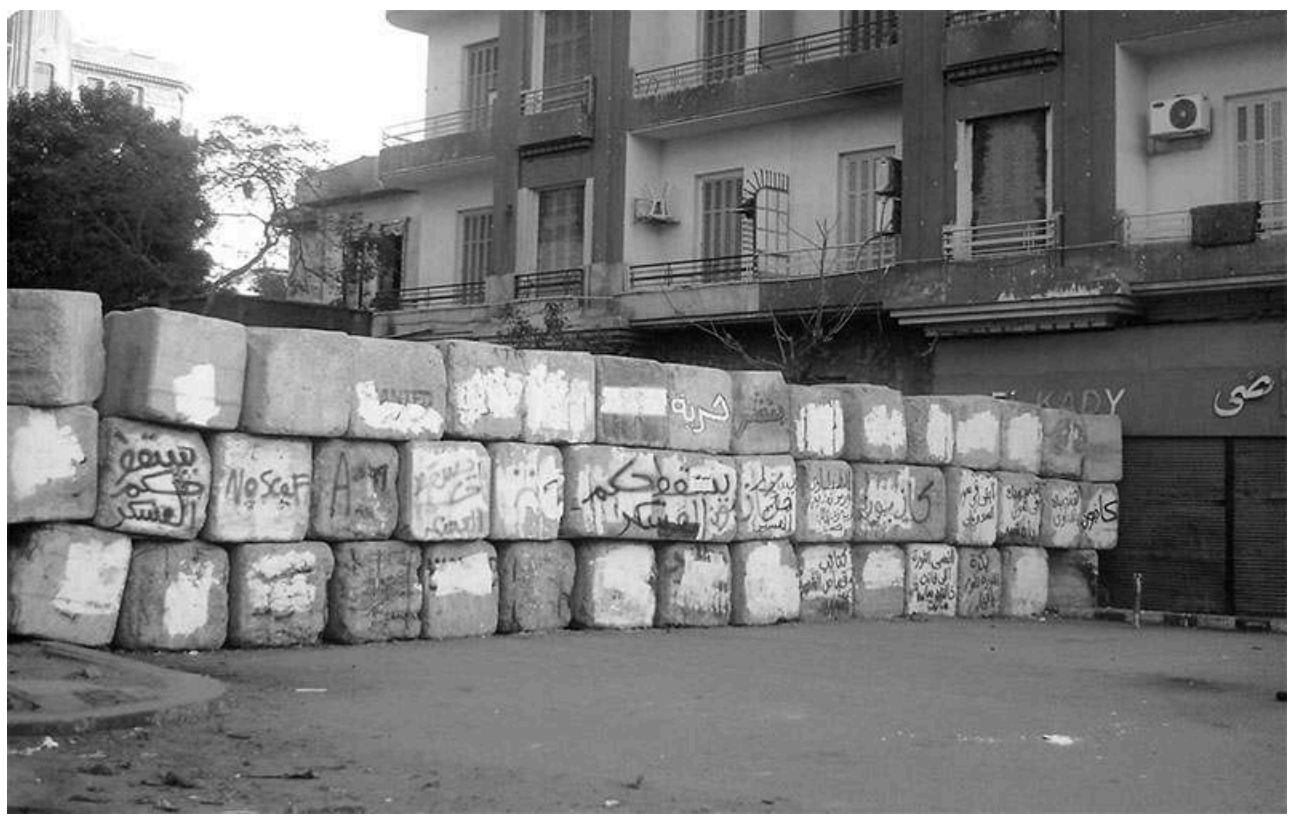

Les trois circonscriptions étudiées ici diffèrent également au niveau de leur taille. Suez est la plus réduite des trois, avec une circonscription au scrutin de liste qui se confond avec la circonscription au scrutin binominal direct à deux tours. Seuls six députés y ont été élus (quatre sur les listes, et deux sur des sièges individuels). La circonscription de Qasr Al-Nîl est plus étendue, puisqu'elle s'est vue octroyer huit sièges à attribuer au scrutin de liste ( $3^{\text {e }}$ circonscription du Caire) et qu'elle est divisée en deux circonscriptions pour le scrutin individuel. Elle est donc représentée à l'Assemblée du peuple par douze députés (huit élus au scrutin de liste et quatre sur des sièges individuels). Dans le cadre de cette enquête, je n'ai suivi les élections au scrutin binominal que dans une seule des deux circonscriptions, celle qui correspond à Qasr AlNîl ( $6^{\mathrm{e}}$ circonscription du Caire), laissant de côté le quartier du Muqattam, rattaché au centre-ville dans le cadre du scrutin de liste, mais composant une circonscription à part dans le cadre du scrutin individuel ${ }^{23}$. Enfin la première circonscription de Gharbiyya est la plus étendue des trois, puisqu'elle dispose de dix sièges au scrutin proportionnel. Divisé en deux circonscriptions de dix sièges chacun au scrutin de liste, le gouvernorat de Gharbiyya est divisé en cinq circonscriptions élisant chacune deux députés au scrutin individuel. Parmi ces cinq circonscriptions, je n'en ai suivi qu'une seule, celle à laquelle appartenait la ville de Tanta ( $1^{\text {er }}$ circonscription), où j'étais basé durant la troisième étape du scrutin.

10 Les tableaux suivants montrent les résultats des élections dans chacune des circonscriptions étudiées ${ }^{24}$ :

Tableau 1 : Résultats des élections au scrutin de liste à Qasr Al-Nîl ( $3^{\mathrm{e}}$ circonscription du Caire)

\begin{tabular}{|c|c|c|}
\hline $\begin{array}{l}\text { Parti ou } \\
\text { coalition }\end{array}$ & $\begin{array}{l}\text { Résultats exprimés en fraction du } \\
\text { corps électoral }\end{array}$ & $\begin{array}{l}\text { Nombre de sièges obtenus par chaque } \\
\text { parti ou coalition }\end{array}$ \\
\hline PLJ & $39,94 \%$ & 3 \\
\hline
\end{tabular}




\begin{tabular}{|l|l|l|}
\hline Bloc Égyptien & $18,33 \%$ & 2 \\
\hline Wafd & $14,67 \%$ & 1 \\
\hline Nûr & $14,52 \%$ & 1 \\
\hline $\begin{array}{l}\text { La révolution } \\
\text { Continue }\end{array}$ & $3,45 \%$ & 1 \\
\hline Wasat & $2,93 \%$ & 0 \\
\hline Total des sièges & & $\mathbf{8}$ \\
\hline
\end{tabular}

Tableau 2 : Résultats des élections au scrutin de liste à Suez

\begin{tabular}{|l|l|l|}
\hline $\begin{array}{l}\text { Parti ou } \\
\text { coalition }\end{array}$ & $\begin{array}{l}\text { Résultats exprimés en fraction du } \\
\text { corps électoral }\end{array}$ & $\begin{array}{l}\text { Nombre de sièges obtenus par chaque } \\
\text { parti ou coalition }\end{array}$ \\
\hline Nûr & $45,55 \%$ & 2 \\
\hline PLJ & $26,84 \%$ & 1 \\
\hline Bloc égyptien & $8,37 \%$ & 1 \\
\hline Wasat & $5,13 \%$ & 0 \\
\hline Wafd & $4,63 \%$ & 0 \\
\hline Total des sièges & & 4 \\
\hline
\end{tabular}

Tableau 3 : Résultats des élections au scrutin de liste dans la $1^{\text {er }}$ circonscription de Gharbiyya

\begin{tabular}{|c|c|c|}
\hline Parti ou coalition & $\begin{array}{l}\text { Résultats exprimés en fraction } \\
\text { du corps électoral }\end{array}$ & $\begin{array}{l}\text { Nombre de sièges obtenus par } \\
\text { chaque parti ou coalition }\end{array}$ \\
\hline Nûr & $29,7 \%$ & 3 \\
\hline PLJ & $28,7 \%$ & 3 \\
\hline Wafd & $13,8 \%$ & 2 \\
\hline Bloc égyptien & $7,4 \%$ & 1 \\
\hline $\begin{array}{l}\text { Réforme et } \\
\text { Développement }\end{array}$ & $4,6 \%$ & 1 \\
\hline $\begin{array}{ll}\text { La } & \text { révolution } \\
\text { continue }\end{array}$ & $3,3 \%$ & 0 \\
\hline
\end{tabular}




\begin{tabular}{|l|l|l|l|}
\hline Wasat & $1,9 \%$ & 0 & \\
\hline Total des sièges & & $\mathbf{1 0}$ & \\
\hline
\end{tabular}

Tableau 4 : Députés élus au scrutin individuel à Qasr Al-Nîl (6 $6^{\mathrm{e}}$ circonscription du Caire), Suez et dans la $1^{\mathrm{er}}$ circonscription de Gharbiyya

\begin{tabular}{|l|l|l|l|}
\hline Circonscription & Siège & Nom du député & Parti \\
\hline Qasr Al-Nîl & fi'ât & Muhammad Abû-Hâmid & Bloc Égyptien \\
\hline Qasr Al-Nîl & ouvriers et paysans & Mustafâ Farghalî & PLJ \\
\hline Suez & fi'ât & 'Abbas 'Abd Al-'Azîz & PLJ \\
\hline Suez & ouvriers et paysans & Hâmid Nûr Al-Dîn & Nûr \\
\hline Gharbiyya I & fi'ât & Muhammad Al-Fiqqî & Wafd \\
\hline Gharbiyya I & ouvriers et paysans & Al-Sayyid Askar & PLJ \\
\hline
\end{tabular}

11 Dans ces élections, la fortune ne suffit pas pour obtenir un siège. Ainsi des candidats très riches, ayant dépensé beaucoup d'argent dans leur campagne, sont balayés dès le premier tour (comme Magdî 'Uthmân à Suez, ou Muhammad 'Urabî à Gharbiyya) ou battus au second (Muhsin Fawzî sur le siège " ouvrier et paysan » de Qasr Al-Nîl). Même cumulé à la notoriété, l'argent ne suffit pas toujours. Ainsi, la très médiatisée Nihâl 'Ahdî, jeune femme de 28 ans, membre de la direction du Jazîra Sporting Club ${ }^{25}$ et candidate du Wafd dans la $6^{\mathrm{e}}$ circonscription du Caire, est battue dès le premier tour. Il est vrai que beaucoup de candidats parmi les plus riches sont soupçonnés, à tort ou à raison, de collusion avec l'ancien régime ${ }^{26}$. Mais même Gamîla Ismâ̂îl, candidate fortunée, présentatrice vedette de la télévision, et ex-femme du candidat à la présidentielle de 2005 Ayman Nûr ${ }^{27}$, a échoué dès le premier tour malgré le soutien de la coalition révolutionnaire ${ }^{28}$. Dans ces élections, la formule gagnante pour remporter un siège en individuel consistait à cumuler d'importantes ressources personnelles, une réputation non-entachée de compromission avec l'ancien régime, et le soutien d'une organisation puissante tant sur le plan national que dans la circonscription visée. 
Figure 2 : Rue Al-Jaych, à l'entrée de la ville de Suez. Les banderoles à l'effigie des candidats occupent tout l'espace disponible (9 décembre 2011)

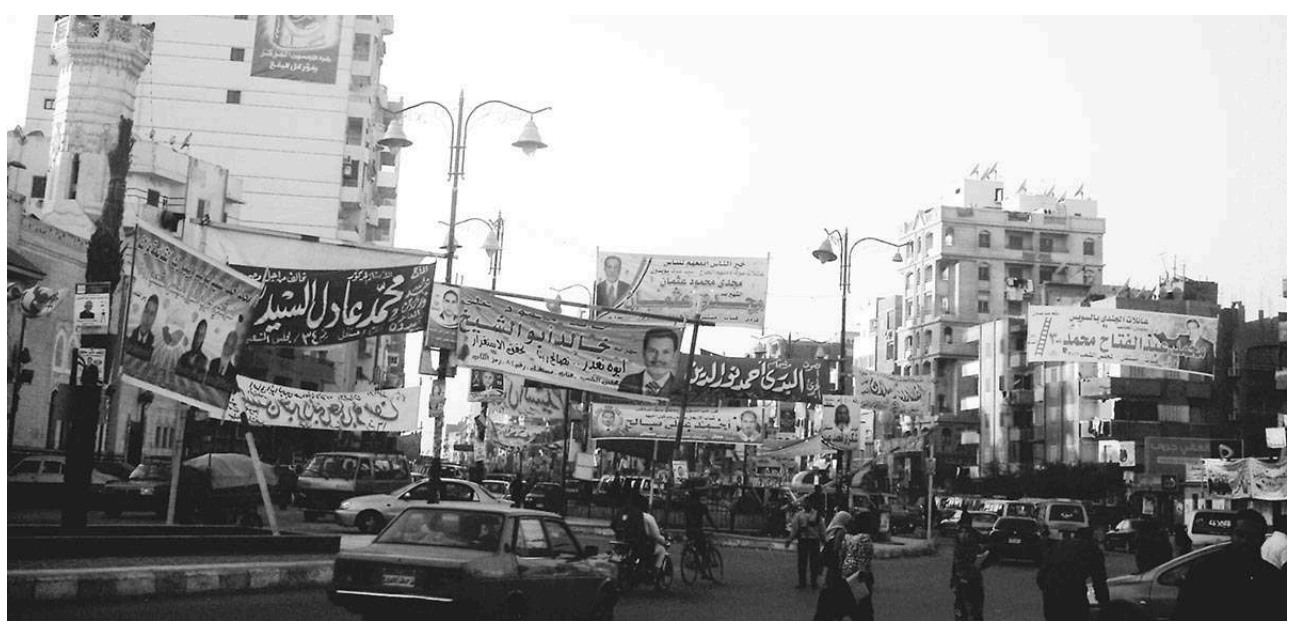

Dans les trois circonscriptions étudiées, les partis sont amenés à faire campagne dans des conditions extrêmement différentes. Ainsi, Qasr Al-Nîl est une circonscription entièrement urbaine, traditionnellement bourgeoise, mais qui a été étendue par la nouvelle loi électorale. Des quartiers aisés (Zamalek, Garden City) y côtoient des zones de peuplement beaucoup plus populaire (Bulâq, 'Abdîn, Mûskî, jusqu'au Muqattam et son fameux quartier des chiffonniers). Du fait des événements de la rue Muhammad Mahmûd, la campagne électorale y tourne court, stoppée par les combats de rue. Ainsi, la principale arène électorale y est-elle l'espace médiatique lui-même, où s'affrontent les candidats les plus célèbres. La circonscription de Suez, quant à elle, se caractérise par une coupure nette entre un seul pôle urbain, la ville de Suez, et la campagne environnante ${ }^{29}$. Le marché électoral y est mis en scène et structure l'espace sur une seule rue (la rue Al-Jaych), autour de la place Arbaîn, au cœur des affrontements de janvier 2011. La plupart des partis et candidats font campagne dans cet espace réduit, sous des tentes dressées pour l'occasion, où l'électeur peut rencontrer les candidats eux-mêmes ou leurs partisans, lire tracts et programmes politiques, et assister à des projections de films de campagne, voire à des meetings électoraux. L'espace y est saturé d'affiches, de banderoles et de véhicules de campagne aux symboles des candidats circulant sans relâche en diffusant slogans et chants à la gloire de leurs favoris. Des rassemblements et des marches (masîra) ponctuelles viennent compléter le tableau ${ }^{30}$. À la sortie de la prière du vendredi, les fidèles sont assaillis par des dizaines de militants de toutes obédiences venus distribuer des tracts sur le parvis de la mosquée. Enfin, la première circonscription de Gharbiyya est de son côté organisée autour de quatre pôles urbains, davantage insérés dans le tissu rural que la ville de Suez ${ }^{31}$. La campagne électorale y est moins concentrée, plus diffuse. Le rôle politique des notables y paraît davantage assumé que dans les environnements urbains. Ainsi, le candidat du Wafd au siège individuel fi'ât est un chef d'entreprise, présenté comme un homme d'affaires davantage qu'un politicien professionnel ${ }^{32}$. Des familles connues ou des professions (le personnel médical de tel hôpital, par exemple) impriment à leurs propres frais des banderoles indiquant qu'elles soutiennent tel ou tel candidat (généralement celui du PLJ), aussi bien dans les villages que dans le centre-ville de Tanta. Autre exemple : lors d'un meeting du Bloc égyptien dans le village de Sibirbây, le parti met en avant le candidat issu de ce village présent sur sa liste, en tenue traditionnelle azharî̉ ${ }^{33}$. 
Figure 3 : Devant le local de la confrérie à Tanta, une banderole déployée par une personnalité locale fait savoir qu'elle soutient les candidats des Frères musulmans ( 6 janvier 2012)

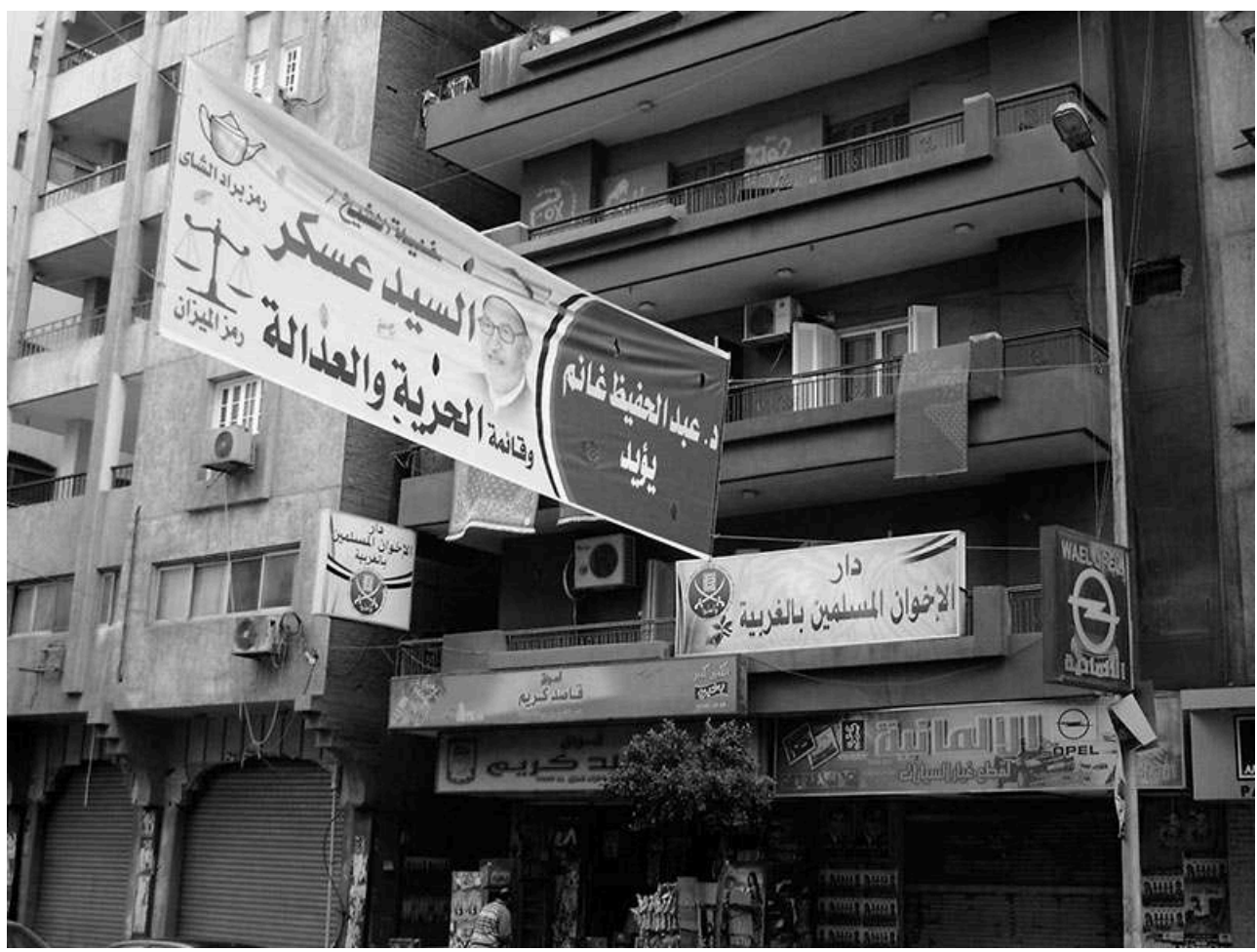

\section{La stratégie des partis et coalitions en lice dans les trois circonscriptions}

Dans la circonscription de Qasr Al-Nîl, et contrairement à la plupart de ses concurrents, le PLJ ne mise pas vraiment sur la carrure médiatique de ses candidats, à l'exception peut-être de l'indépendant libéral Wahîd 'Abd Al-Magîd, coordinateur général de la "Coalition Démocratique " qui rassemble une trentaine de partis autour des Frères musulmans. De par sa position dans la campagne nationale, Wahîd 'Abd Al-Magîd est particulièrement visible dans les médias, et il occupe la première place sur la liste du PLJ. Dans cette circonscription, les Frères font une campagne de terrain, occupant l'espace avec leurs bannières plastifiées, leurs tracts dans les rues et chez de nombreux commerçants, et les voitures munies de haut-parleurs rappelant aux électeurs que «le parti de la Liberté et de la Justice est le parti des Frères musulmans ${ }^{34}$. Moins présents dans les médias que leurs adversaires, ils le sont davantage dans la rue. Surtout, ils sont en avance, n'attendant pas le coup d'envoi de la campagne officielle. Les événements de la rue Muhammad Mahmûd achèveront d'ailleurs de réduire à néant les chances de leurs concurrents de rattraper leur retard. Cette stratégie permet à leur liste de se classer au premier rang, avec près de $40 \%$ des suffrages exprimés, et à leurs candidats de se qualifier pour le second tour sur les deux sièges en jeu au scrutin binominal. Parmi les circonscriptions étudiées, c'est à Suez que la confrérie est la plus faible. Si la tête de liste du PLJ, Ahmad Mahmûd, est une personnalité unanimement respectée, les Frères musulmans n'ont commencé à s'organiser dans cette ville qu'après le retrait des troupes israéliennes, au milieu des années 1970. Ils ont alors eu à faire avec la concurrence des salafistes, qui s'y sont au contraire développés précocement ${ }^{35}$. Par 
ailleurs, la confrérie a échoué à s'implanter en milieu ouvrier - fait que reconnaissent d'ailleurs volontiers ses partisans -, ce qui ne peut que jouer en sa défaveur dans une circonscription où l'industrie occupe une place centrale. Du fait de ces faiblesses, le parti de la Liberté et de la Justice a du mal à tenir ses alliés. Ainsi, alors même que la troisième position sur la liste du PLJ est occupée par une candidate du parti libéral Ghad Al-Thawra, ce parti a laissé deux de ses membres se présenter sur les sièges individuel ${ }^{36}$, contre les deux candidats que le PLJ y présente au nom de la coalition démocratique, alliance électorale à laquelle appartient pourtant le Ghad Al-Thawra. Rassemblant à peine plus du quart des électeurs sur leur liste, les Frères n'obtiennent qu'un seul siège à la proportionnelle, et un second sur le siège individuel des fi'ât. Par contre, leur candidat au siège " ouvrier et paysan » ne parvient pas à se qualifier pour le second tour. Enfin, à Gharbiyya, les Frères musulmans semblent jouer à domicile. Leur campagne s'appuie particulièrement sur les services qu'ils rendent à la collectivité. Ainsi, ils disposent à Tanta d'une école, d'une mosquée, d'une pharmacie et même d'un opticien, concentrés autour de ce qui constitue le cœur de leur dispositif dans la ville, l'hôpital Tîba. Ce système, particulièrement bien rôdé dans ce gouvernorat, leur permet à la fois de fidéliser leurs sympathisants des classes moyennes en leur fournissant un travail ${ }^{37}$ et de mobiliser en leur faveur les citoyens des classes populaires en les soignant et en éduquant leurs enfants pour un prix modeste ${ }^{38}$. Il faut d'ailleurs ajouter à ce dispositif médical et éducatif un volet proprement caritatif, passant par le contrôle d'ONG de développement et de centres de la zakât $t^{39}$. L'autre pilier de l'influence frériste dans la circonscription est le réseau d'écoles azharites, qui scolarisent de nombreux écoliers dans le Delta. L'université d'Al-Azhar dispose d'une faculté de droit musulman dans le village de Sibirbây. Si les Frères ne contrôlent pas l'institution d'Al-Azhar, ils sont néanmoins largement représentés parmi son corps professoral. Leur candidat individuel pour le siège «ouvrier et paysan ", le sheikh Al-Sayyid 'Askar est d'ailleurs un ancien dirigeant de premier plan de l'institution, au niveau national. L'efficacité de leur dispositif permet aux Frères de rassembler près de $30 \%$ des voix sur leur liste, arrivant ainsi juste derrière le parti Nûr, et conquérant trois sièges de députés sur les dix pourvus à la proportionnelle. Surtout, Al-Sayyid 'Askar rallie sur sa personne plus de $50 \%$ des suffrages dès le premier tour. Il est vrai qu'il n'a pas eu à affronter de candidat salafiste, suite à un accord de désistement réciproque passé entre le PLJ et le parti Nûr: le siège " ouvrier et paysan " pour le premier et le siège fi'ât pour le second. 
Figure 4 : Fresques peintes sur la façade de "l'école de la génération musulmane ${ }^{40}$, contrôlée par les Frères musulmans, à proximité de l'hôpital Tîba de Tanta (2 janvier 2012)

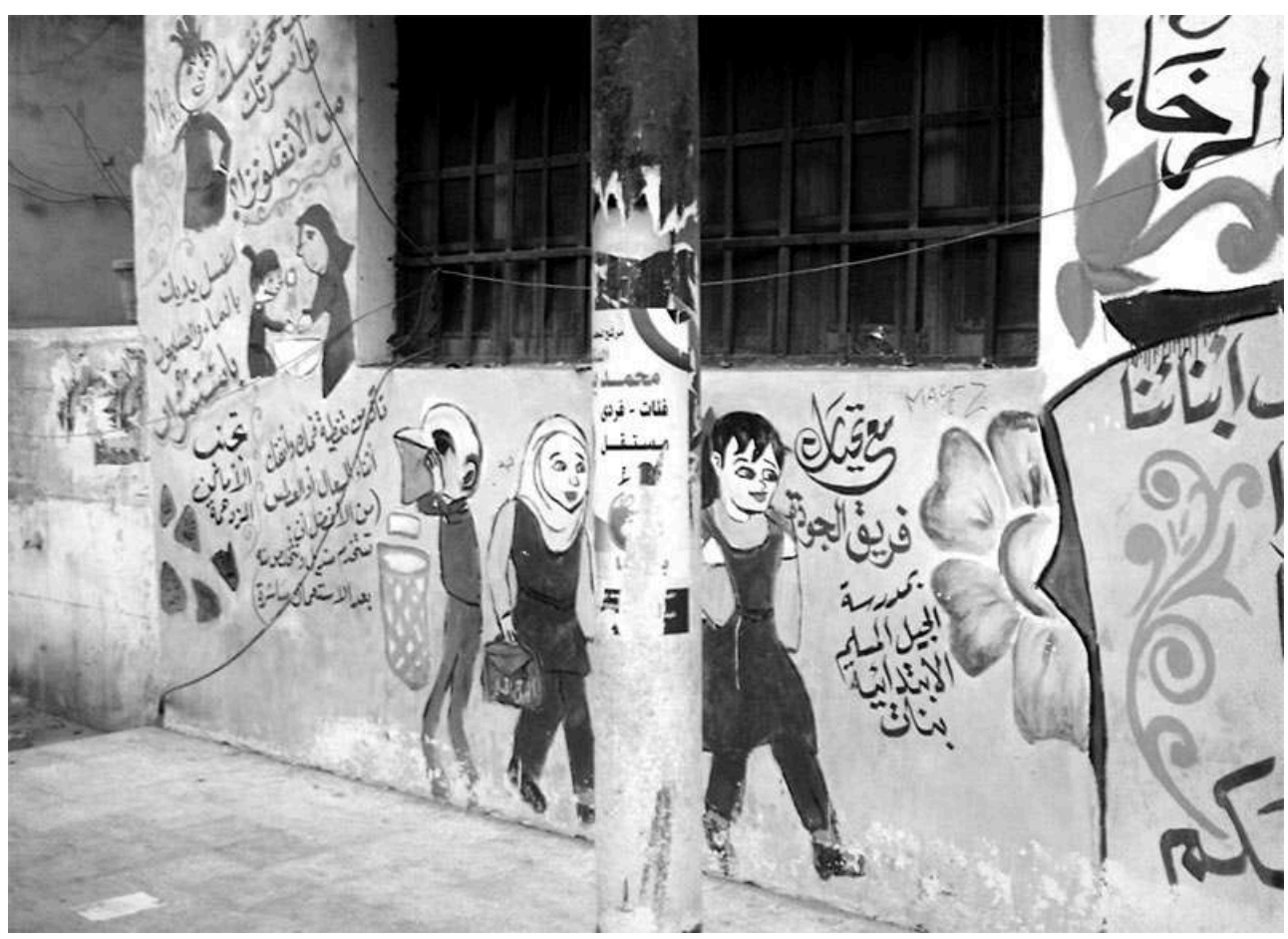

Parmi les trois circonscriptions étudiées, la coalition salafiste a réalisé sa plus mauvaise performance dans la circonscription urbaine de Qasr Al-Nîl, où elle n'a obtenu que $15 \%$ des voix au scrutin de liste (se classant ainsi au quatrième rang) et où aucun de ses candidats n'a pu accéder au second tour sur les sièges individuels. Les salafistes ont en effet réalisé leurs meilleurs scores dans les zones rurales, telles que le gouvernorat de Gharbiyya ${ }^{41}$, où ils sont arrivés en tête du scrutin de liste avec près de $30 \%$ des voix. Par ailleurs, leur unique candidat sur un siège individuel, Midhat Mich'al, s'est aisément qualifié pour le second tour. Celui-ci a néanmoins été victime d'une manœuvre politique des Frères musulmans, qui ont appelé à voter pour son adversaire Muhammad Al-Fiqqî, candidat du Wafd, après s'être placés à l'abri des représailles de leur ancien allié en parvenant à faire élire dès le premier tour leur candidat sur le siège « ouvrier et paysan $»^{42}$. Mais c'est dans la circonscription de Suez que les salafistes réalisent leur score le plus impressionnant. Avec $45,55 \%$ des voix, leur liste fait presque deux fois mieux que le PLJ, et leur permet de conquérir deux sièges sur les quatre attribués à la proportionnelle dans la circonscription. Leurs candidats se qualifient par ailleurs au second tour sur les deux sièges individuels. Si Muhammad Âdil, membre du parti Construction et Développement ${ }^{43}$, est finalement battu par le candidat du PLJ sur le siège fi'ât, le salafiste Hamî Nûr Al-Dîn parvient à arracher le siège " ouvrier et paysan " à l'ancien député 'Abd Al-Hamîd Kamâl, candidat du parti de gauche Al-Tagammu', disposant pourtant de nombreux soutiens en milieu ouvrier. Dans cette circonscription, en effet, les salafistes disposent d'une implantation ancienne, symbolisée par le sheikh Hâfiz Salâma qui avait pris la tête de la résistance à l'occupation israélienne suite à la défaite de 1967. Ils ont pu en outre profiter des faiblesses de l'organisation frériste, ainsi que des erreurs des partis concurrents, qui ont concentré l'essentiel de leurs forces dans le centre-ville de Suez, négligeant ainsi la campagne environnante ${ }^{44}$. 
Le vieux parti libéral du Wafd, issu de la révolution de 1919 visant à libérer l'Égypte de la tutelle britannique, représente traditionnellement les intérêts de la bourgeoisie terrienne, dont l'influence sociale a beaucoup diminué depuis la révolution de 1952. Peu implanté à Suez, il y obtient moins de $5 \%$ des voix au scrutin de liste, et n'y remporte aucun siège. À Qasr Al-Nîl et Gharbiyya, il réalise de bien meilleurs scores, avec près de $15 \%$ des voix et respectivement un et deux sièges au scrutin de liste. Sur les sièges individuels, le Wafd opte pour deux stratégies opposées dans ces deux circonscriptions. À Qasr Al-Nîl, il accorde son investiture à la jeune et médiatique Nihâl 'Ahdî, sans véritable expérience politique et ancienne détentrice d'une carte du PND. L'attention des médias est encore renforcée par la présence d'une seconde candidate jeune et non-voilée, la présentatrice de télévision Gamîla Ismâîll. Les journalistes se plaisent alors à mettre en scène un supposé duel entre les deux femmes, parfois présenté comme une manifestation de "jalousie féminine». Cette stratégie de médiatisation s'avère au final peu payante, puisque Nihâl 'Ahdî échoue à se qualifier pour le second tour. Au contraire, dans la première circonscription de Gharbiyya, où il a su s'attirer l'estime de la jeunesse révolutionnaire en refusant de se prêter au recyclage de tout ce qui pourrait s'apparenter à un fulûl, le Wafd accorde son investiture à un homme d'affaires d'âge mûr, membre du comité central du parti, Muhammad AlFiqqî. À la tête d'une entreprise de commercialisation de matériel médical, avec un pied au Caire et un autre à Tanta, investissant une partie de ses bénéfices dans des activités caritatives, cet homme présente toutes les caractéristiques du notable de province, capable une fois élu de mobiliser une partie des ressources du centre au profit de sa circonscription. En outre, il est parvenu à habiter ce rôle tout en conservant une réputation sans taches en matière de corruption et de compromissions avec l'ancien régime. Bien qu'impliqué dans l'organisation du parti à l'échelon national, il fait campagne à part, dans son propre local, distinct - mais à proximité - de celui du Wafd. Il n'est d'ailleurs jamais fait mention de ce dernier sur le matériel de campagne du candidat, néanmoins capable de mobiliser les ressources du parti en plus des siennes propres en faveur de sa candidature. Sans débauche apparente de moyens, cette stratégie le mène au second tour, où l'appui des Frères musulmans, désireux de réduire l'influence de leurs concurrents salafistes dans le gouvernorat, lui permet de l'emporter face au candidat du parti Nûr. 
Figure 5 : Affiches de campagne de Gamîla Ismâîl (à gauche) et de Nihâl 'Ahdî (à droite), dans le quartier de Zamalek (25 novembre 2011 )
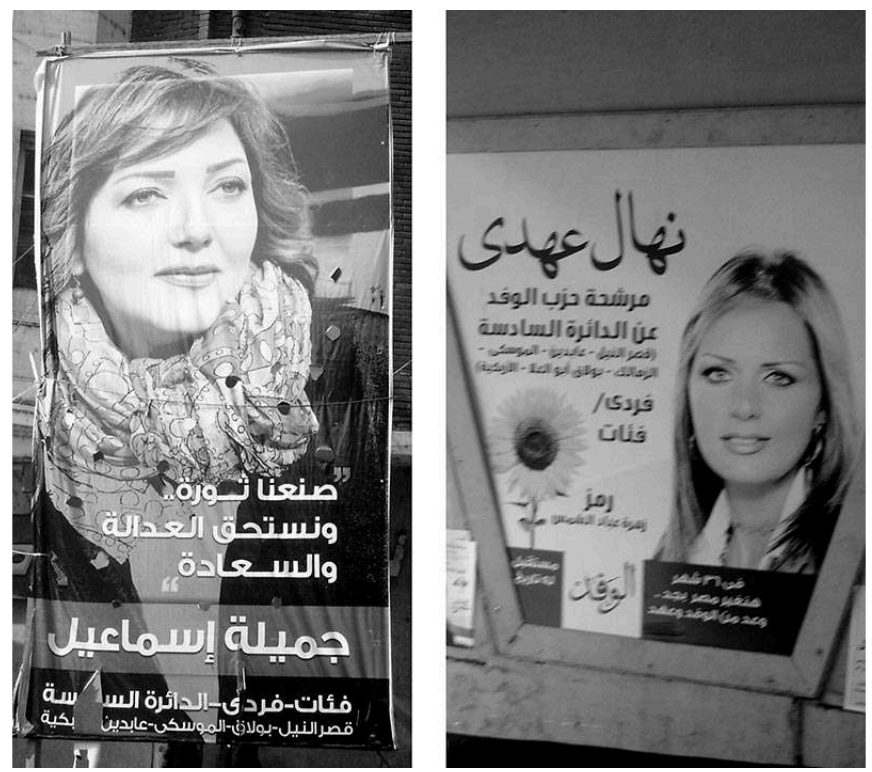

Le Bloc égyptien est une coalition de partis rassemblant le parti des Égyptiens libres (créé par l'homme d'affaires copte Nagîb Sâwîris), et deux partis socialistes: le parti égyptien social-démocrate et le Tagammu. Alors que la coalition démocratique présente partout des listes aux couleurs du seul PLJ - sur lesquelles ont été répartis des candidats des partis alliés -, et que la « coalition pour l'Égypte » (salafiste) fait de même avec le parti Nûr, le Bloc égyptien a opté pour la formule inverse. Les partis qui le composent se sont réparti les circonscriptions (50\% pour les Égyptiens libres, $40 \%$ pour les sociaux-démocrates et $10 \%$ pour le Tagammu), présentant partout des listes homogènes, aux couleurs de la coalition ${ }^{45}$. Dans chacune des trois circonscriptions étudiées, c'est le parti des Égyptiens libres, économiquement et politiquement libéral, qui a conduit les listes du Bloc ${ }^{46}$. Il y a obtenu un succès variable, avec un siège de député à Gharbiyya $(7 \%)$ et un autre à Suez $(8 \%)$. C'est à Qasr Al-Nîl que le parti a réalisé son meilleur score, en se classant au second rang, avec $18 \%$ et deux députés élus au scrutin de liste. Dans la sixième circonscription du Caire, le parti est en outre parvenu à faire élire un candidat individuel au siège fi'ât, Muhammad Abû Hâmid, alors âgé de 38 ans. Sans expérience politique préalable à la révolution, celui-ci a longtemps milité dans une ONG de développement. Lorsque le parti des Égyptiens libres est créé en 2011, il devient membre de son comité central et participe à la rédaction de son programme. Bon connaisseur de la religion musulmane, il se présente comme le candidat du dialogue inter-religieux et de l'État civil. Très présent dans les médias, son positionnement lui permet de rassurer les chrétiens sans s'aliéner ses coreligionnaires musulmans. Nombre de ces derniers, vivant dans les quartiers aisés de la circonscription, considèrent d'ailleurs les islamistes comme une menace pour leur mode de vie, et sont en conséquence enclins à accorder leur voix à un libéral. Sa jeunesse enfin, et son discours sans concessions à l'égard des brutalités policières, lui attirent la sympathie des électeurs révolutionnaires, surtout après l'élimination de Gamîla Ismâîll, lors du second tour qui l'oppose à un candidat frériste. Le parti des Égyptiens libres a pourtant adopté des stratégies très similaires dans les trois circonscriptions, composant ses listes en recrutant des petits notables locaux, sans se montrer trop regardant sur leur rôle politique passé. Cette stratégie a permis au parti 
de disposer de relais locaux dans plusieurs quartiers de chaque circonscription où il se présentait, et de les utiliser pour faire rapidement connaître auprès des électeurs le nom, les grandes lignes du programme et les symboles de l'organisation. En fait, la différence entre les résultats obtenus par ce parti à Qasr Al-Nîl et dans les deux autres circonscriptions reflète l'écart entre les résultats globaux qu'il a enregistrés lors de la première phase de ces élections et les deux suivantes. Si cet écart peut sans doute en partie s'expliquer par le caractère beaucoup plus urbain des premières zones à avoir voté, il semblerait cependant que l'essentiel soit ailleurs. C'est sans doute ici que la réduction de l'incertitude au cours des étapes du scrutin a produit ses effets les plus spectaculaires. Se classant troisième, derrière le PLJ et le Nûr, lors de la première phase, le Bloc Égyptien est également apparu à cette occasion comme "le parti des chrétiens ». Il est vrai que ses candidats avaient beaucoup joué sur cette corde auprès des électeurs coptes, et que le soutien de l'Église au Bloc, et en particulier au parti des Égyptiens libres, n'avait pas fait l'objet de beaucoup de mystères. Les islamistes ont alors commencé à utiliser cet argument contre le Bloc. Par ailleurs, la médiatisation à desservi cette coalition en la réduisant à sa figure médiatique la plus visible, l'homme d'affaires chrétien Nagîb Sâwîris, et à ses maladresses ${ }^{47}$. De ce fait, durant la deuxième étape des élections, beaucoup d'électeurs libéraux ont commencé à identifier le Bloc égyptien comme un parti confessionnel, au même titre que les partis islamistes. Ses résultats ont alors décru au profit du Wafd, qui s'est ainsi hissé à la troisième place, alors qu'il n'avait été que le quatrième parti lors de la première phase des élections.

Figure 6 : Deux banderoles du Bloc égyptien devant une église à Suez. Le message se veut sans équivoque (9 décembre 2011)

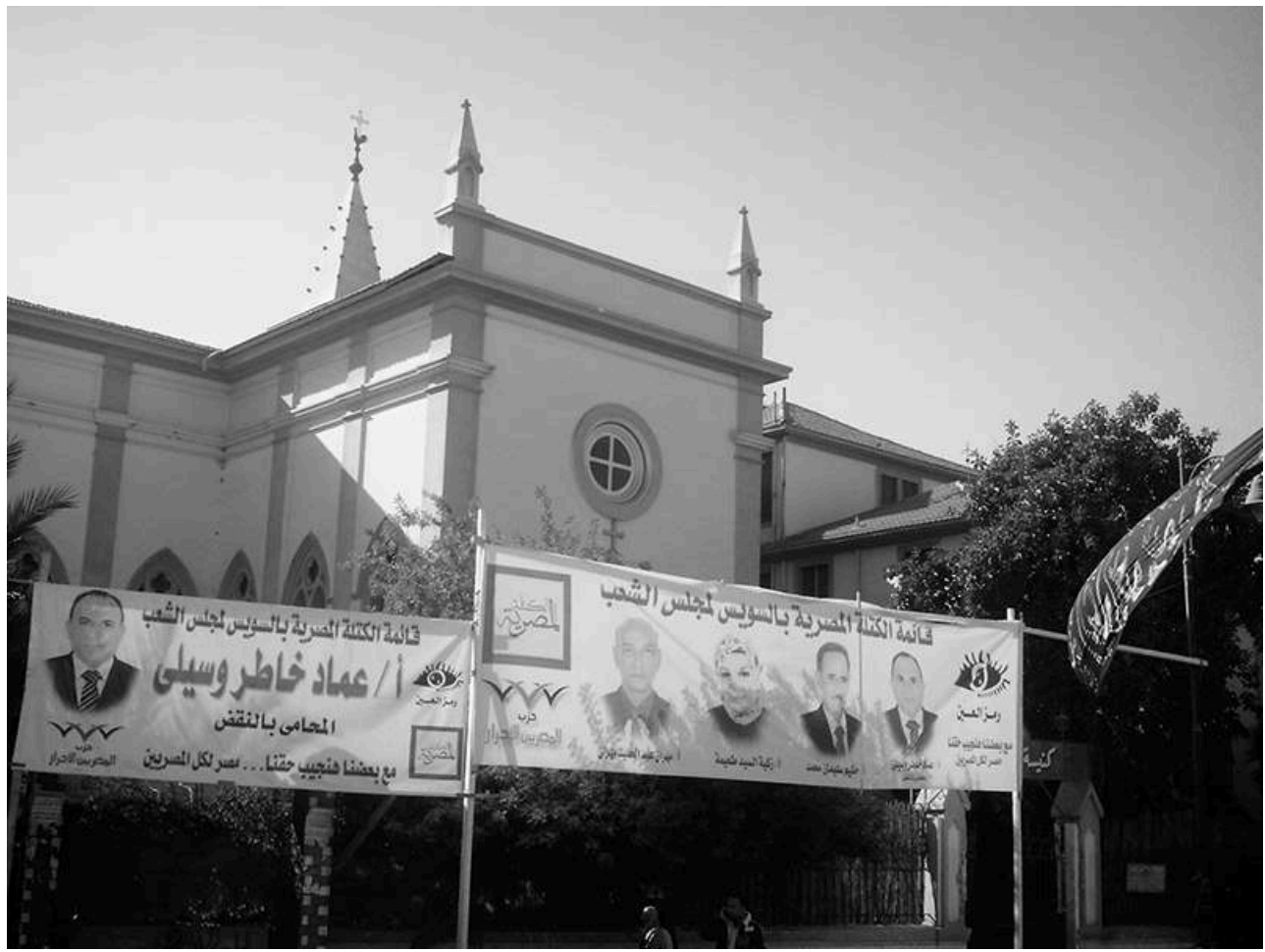

17 Avec près d'un million d'électeurs, et seulement une dizaine de députés, le parti islamiste modéré du Wasat $^{48}$ a occupé la cinquième place lors de ces élections. Néanmoins, il n'a obtenu aucun siège dans les trois circonscriptions étudiées ici. Ce parti était quasiment absent de Gharbiyya, où il a tout juste été en mesure de composer 
une liste, mais pas de mener campagne en sa faveur. Son score n'y atteint même pas la barre des $2 \%$. De manière plus surprenante, la campagne menée par le Wasat à Qasr AlNîl était très modeste, et semblait manquer de moyens. Sa tête de liste, 'Amrû Fârûq, un jeune quadragénaire travaillant dans une société de communication, n'est pas parvenu à se faire une place dans un espace déjà saturé de jeunes candidats fortement médiatisés. Au niveau national d'ailleurs, la campagne médiatique du Wasat a été davantage axée sur la presse papier que sur la télévision, ce qui dénote sans doute un relatif manque de moyens financiers (les publicités dans les journaux coûtent moins cher que la diffusion de clips de campagne sur les chaînes privées). Il n'y a qu'à Suez que ce parti a su occuper le terrain dans la rue, en dressant sa tente de campagne dans un lieu hautement symbolique - devant les ruines calcinées du commissariat de la place Arbaî̀ -, en faisant circuler en permanence plusieurs véhicules de campagne, en distribuant en abondance tracts et drapeaux aux couleurs du parti, en organisant enfin un meeting sous les auspices de ses dirigeants nationaux. Ces efforts lui ont permis de dépasser le seuil symbolique des $5 \%$ au scrutin de liste, faisant ainsi du Wasat le quatrième parti de Suez. La configuration locale - mise en scène d'un marché électoral s'inscrivant dans l'espace physique de la rue - a sans doute bénéficié à ce parti disposant d'une identité programmatique forte, et misant sur la compétence et la respectabilité de ses candidats davantage que sur leur fortune personnelle et leur ancrage local. Cependant, seuls quatre sièges étant en jeu à la proportionnelle, ce relatif succès ne s'est pas traduit par l'envoi d'un député à l'Assemblée du peuple.

Figure 7 : La tente de campagne du Wasat à Suez (9 décembre 2011)

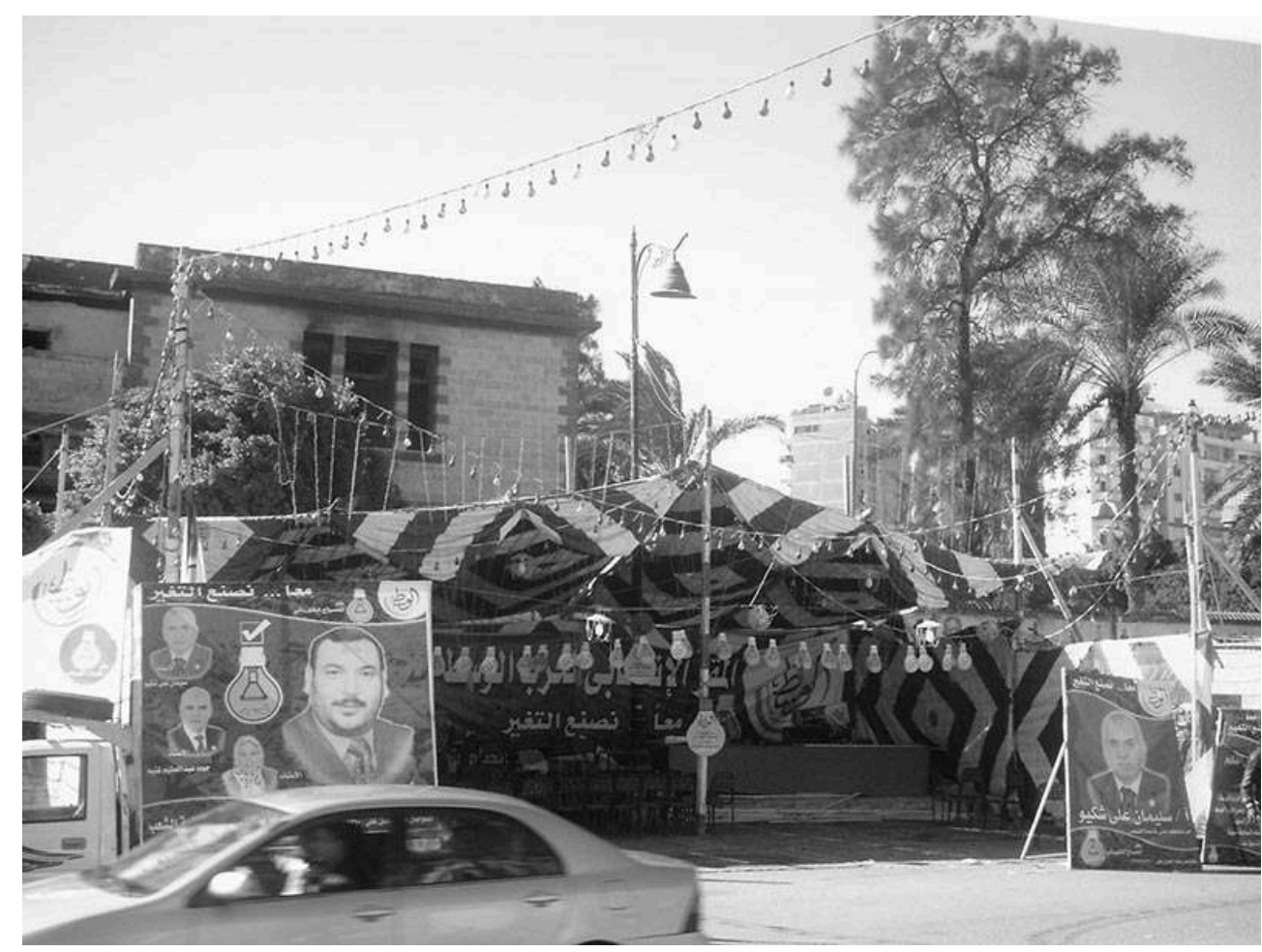

Les partis issus du défunt PND étaient absents à Qasr Al-Nîl, et si le parti des Conservateurs et le parti de la Libertét ${ }^{49}$ ont présenté chacun une liste à Suez, ils n'y ont quasiment pas fait campagne et leurs voix cumulées ne franchissent pas la barre des $2 \%$. Dans la première circonscription de Gharbiyya, les choses sont légèrement 
différentes : à eux deux, ces partis rassemblent plus de $5 \%$ des voix. Il faut dire que la tête de liste du parti de la Liberté en est un des dirigeants nationaux, ancien député PND, et qu'il n'a pas hésité à mettre de l'argent dans sa campagne. Par ailleurs, parmi les trois circonscriptions étudiées, seule celle-ci voit le parti de la Réforme et du Développement obtenir un siège, avec presque $5 \%$ des voix. Or, même sans être issue directement de l'ancien parti hégémonique, cette organisation a partie liée avec certains responsables de l'ancien régime. Quelques mois plus tard, c'est dans le gouvernorat de Gharbiyya que Ahmad Chafîq, l'ancien ministre de Moubarak, réalisera ses meilleurs scores au second tour de la présidentielle.

Enfin, la coalition de "la révolution continue " n'a réussi à obtenir qu'un seul siège dans les trois circonscriptions qui nous intéressent ici. C'est à Qasr Al-Nîl que cette coalition a pu, avec moins de $4 \%$ des voix, envoyer un député à l'assemblée grâce à la règle du plus fort reste. Dans cette "circonscription du feu et du sang", où la révolution continuait bel et bien quelques jours encore avant le premier tour du scrutin, l'alliance électorale des partis et organisations révolutionnaires a joué le jeu de la médiatisation en soutenant la candidature de la présentatrice vedette Gamîla Ismâ îl au siège fi'ât, mais aussi en confiant la tête de sa liste à l'actrice Taysîr Fahmî. Si, avec près de $20 \%$ des voix, la première a manqué de peu sa qualification au second tour, le score obtenu par la liste révolutionnaire demeure décevant étant donné le contexte. "La révolution continue " a obtenu un score quasiment équivalent dans la première circonscription de Gharbiyya, où sa liste rassemblait des jeunes révolutionnaires libéraux, socialistes et islamistes, et était conduite par un membre du parti du Courant égyptien ${ }^{50}$. Enfin à Suez, ville-symbole de la révolution, la coalition révolutionnaire n'a paradoxalement pas présenté de liste. En effet, il s'est avéré que l'un des membres pressentis pour y figurer, la militante ouvrière Nâhid Marzûq, avait autrefois appartenu au PND du fait de ses responsabilités locales dans le syndicat ouvrier officiel. C'est pour cette raison que les autres membres de la coalition se sont retirés de la liste. Membre du parti de la coalition socialiste, Nâhid Marzûq a finalement fait campagne en individuel pour le siège "ouvriers et paysans ». Un autre candidat révolutionnaire, Ahmad Fathî, membre d'un mouvement de jeunes propre à la ville de Suez ${ }^{51}$, s'est également porté candidat, ainsi que Sa ûd 'Umar, ouvrier retraité proche des socialistes révolutionnaires. Aucun des trois n'a cependant réalisé de score significatif.

\section{Conclusion}

La baisse relative de l'incertitude au cours des trois étapes du processus électoral a sans doute eu pour premier effet de diminuer le poids électoral du Bloc égyptien, et en particulier du parti des Égyptiens libres. Par ailleurs, lorsqu'il est apparu que la force des partis islamistes dans les urnes avait été largement sous-estimée, certains candidats et certaines organisations ont jugé utile d'islamiser quelque peu leur image. Ainsi, lors du meeting du Wasat à Suez, la tête de liste du parti, 'Isâm Chibl, a scandé de virulents "Allâh akbar!» afin de chauffer la foule. Durant la troisième étape des élections, à Gharbiyya, le parti des Égyptiens libres s'est montré très soucieux de corriger son image de "parti des chrétiens » : la musique de campagne diffusée par les camions et dans les meeting reprenait une chanson dont le refrain débutait par "Bismillâh, bismillâh, Allâh Akbar... ${ }^{52}$. Lors d'un meeting de ce parti dans le village de Sibirbây, comportant pourtant une forte minorité copte, un seul orateur chrétien a pris la 
parole, pour à peine quelques minutes. A contrario, des sheikh d'Al-Azhar y ont abondamment cité le Coran, y compris le fameux verset déclarant que Dieu n'a pas engendré ${ }^{53}$.

L'effet le plus visible de la médiatisation de certaines circonscriptions est qu'elle a conduit de nombreux partis à se fourvoyer dans leurs choix stratégiques. Ainsi, la loupe médiatique braquée sur Qasr Al-Nîl et « le grand souk électoral $»^{54}$ implanté au cœur de Suez ont en partie masqué le patient travail de terrain mené par les Frères musulmans et les salafistes depuis des années (constitution d'un réseau d'institutions sociales, contrôle des mosquées) et durant la campagne (les militantes islamistes notamment, ont réalisé un important travail de porte-à-porte, visant principalement les femmes au foyer). Cet écart entre la mise en scène de la campagne et la réalité a été particulièrement brutal à Suez. Du point de vue des militants faisant campagne au centre-ville, le parti Nûr se présentait comme un parti parmi d'autres, disposant d'une tente de campagne sur la rue Al-Jaych où l'on pouvait récupérer des tracts électoraux. L'observateur extérieur, journaliste ou chercheur, n'échappait d'ailleurs pas à cette illusion. L'annonce des résultats y a donc provoqué un choc, tant la disproportion des forces en faveur des salafistes était inattendue. Au final, dans les trois circonscriptions étudiées, seul Muhammad Abû Hâmid à Qasr Al-Nîl semble avoir profité de sa notoriété médiatique, et encore a-t-il bénéficié lui aussi du travail de proximité réalisé par les militants du parti des Égyptiens libres dans le cadre de la promotion de leur liste.

Si l'influence des médias doit être relativisée, car elle ne remplace pas plus le travail de terrain que la proximité avec les électeurs et la capacité à leur rendre des services, elle ne doit néanmoins pas être négligée. Les circonscriptions au scrutin de liste étaient très larges, et les électeurs ne connaissaient pas la plupart des candidats. Dès lors, l'image du parti ou de la coalition s'est avérée déterminante dans leur choix. Les atouts médiatiques du Wafd et du Bloc égyptien ne sont ainsi sans doute pas étrangers à leur capacité à s'imposer comme les deux principales forces d'opposition parlementaire à la majorité islamiste. Le Wafd est en effet le seul, parmi les partis libéraux, à disposer d'un journal quotidien, et son président, Al-Sayyid Badawî, possède en propre un autre quotidien, Al-Dustûr, et une chaîne de télévision, Al-Hayât. Comparativement aux autres partis libéraux, le Wafd et le parti des Égyptiens libres disposent en outre d'une force de frappe financière impressionnante, qui s'est traduite principalement par la diffusion de clips télévisés et la location de panneaux publicitaires grand format. Bien que disposant d'autres moyens d'atteindre les électeurs, les islamistes ont dû se battre eux aussi sur ce front, en participant aux différents talk-shows ${ }^{55}$ et en diffusant eux aussi des clips de campagne sur les chaînes de télévision et les réseaux sociaux ${ }^{56}$. Les autres partis ont eu beaucoup de difficultés à faire face à cette débauche de moyens, même si quelques personnalités ont su tirer leur épingle du jeu médiatique, notamment parmi les candidats identifiés comme des révolutionnaires ${ }^{57}$. 


\section{BIBLIOGRAPHIE}

BERQUE J., 1967, L'Égypte, Impérialisme et Révolution, Paris, NRF Gallimard.

BLAYDES L. \& EL TAROUTY S., 2009, “Women's Electoral Participation in Egypt: The Implications of Gender for Voter Recruitment and Mobilization", The Middle East Journal, vol. 63, n³, p. 364-380.

BRUYAS F., 2002, De la re-construction régionale à formation d'un territoire du canal de Suez: Acteurs et enjeux, thèse de géographie soutenue en novembre 2002 à l'université François Rabelais de Tour.

CATUSSE M., 2000, « Économie des élections au Maroc », Maghreb-Machrek, n 168, p. 51-66.

CLARK J. A., 2004, "Movement Theory and Patron-Clientelism: Islamic Social Institutions and the Middle Class in Egypt, Jordan and Yemen", Comparative Political Studies, vol. 37, p. 941-968.

Gamblin S. (dir.), 1997, Contours et détours du politique en Égypte. Les élections législatives de 1995, Paris, L'Harmattan/Cedej.

- 1997, « Familles, pouvoir et territoires : les élections législatives de 1995 dans une circonscription de Haute-Égypte », in GAMBLIN S. (dir.), op. cit., p. 313-337

Kohstall F. \& Vairel F. (dir.), 2011, « Fabrique des élections », Égypte/Monde arabe, vol. 3, nº 7.

PAGÈs EL-KAROUI D., 2008, Villes du delta du Nil. Tantâ, Mahalla, Mansûra, Cités de la densité, Paris, CEDEJ/Karthala/IISMM.

ROKKAN S. \& VALEN H., 1962, “The Mobilization of the Periphery: Data on Turnout, Party Membership and Candidate Recruitment in Norway", Acta Sociologica, vol. 6, n 1-2, p. 111-158. Soliman S., 2012, « Les nouvelles forces “civiles” égyptiennes face au défi électoral », Confluences Méditerranée, vol. 82, p. 161-169.

STEUER C., 2012, « Le printemps des partis ? Le rôle des organisations partisanes égyptiennes dans la mobilisation électorale », Confluences Méditerranée, n 82, p. 91-105.

- 2013, « S'approprier un nom pour occuper un espace : Le parti du centre en Égypte », Mots. Les langages du politique, $\mathrm{n}^{\circ} 101, \mathrm{p} .113-126$.

VANNETZEL M., 2007, « “Ils nous ont déjà essayés !” Clientélisme et mobilisation électorale frériste en Égypte », Politique africaine, vol. 108, p. 47-66.

\section{NOTES}

1. Encore qu'ils aient dû partager cette dernière fonction avec d'autres organisations (Frères musulmans, Prédication salafiste, voire entreprises privées, etc.) Cf. Clément Steuer, «Le printemps des partis? Le rôle des organisations partisanes égyptiennes dans la mobilisation électorale ", Confluences Méditerranée, $\mathrm{n}^{\circ}$ 82, 2012.

2. Certains d'entre eux étaient d'ailleurs des membres de partis politiques qui ont enregistré leur candidature en tant qu'indépendants...

3. Voir notamment le travail désormais classique de Stein Rokkan et Henry Valen, "The Mobilization of the Periphery: Data on Turnout, Party Membership and Candidate Recruitment in Norway", Acta Sociologica, 1962, vol. 6, n 1-2.

4. Leur influence sur le comportement des électeurs ne peut quant à elle être appréhendée, en l'absence de données économiques, démographiques et sociologiques fiables sur chacune des 
circonscriptions étudiées, et sur la répartition des votes à un niveau plus fin que celui de la circonscription. Le décompte des bulletins s'est en effet fait au niveau de la circonscription pour les élections législatives, et non pas bureau de vote par bureau de vote.

5. Depuis l'introduction du scrutin majoritaire en 1990, il existait néanmoins une incertitude au niveau local, croissante dans le temps, à mesure que les candidatures des « indépendants sur les principes du PND» se multipliaient. Dans les années 1990-2000, il y a toujours davantage de concurrence entre des candidats indépendants qui, presque tous, rejoindront le PND une fois élus. L'hégémonie du parti dominant au parlement demeure ainsi garantie, bien que les noms des députés victorieux soient soumis aux aléas du scrutin.

6. Ce qui constitue en revanche un élément de continuité par rapport aux précédentes élections. Voir le numéro d'Égypte/Monde arabe, 2011, vol. 3, n 7, coordonné par Florian Kohstall et Frédéric Vairel.

7. Le 25 septembre 2011, l'article 38 de la déclaration constitutionnelle est amendée afin de prémunir contre tout recours judiciaire la décision d'attribuer les deux tiers des sièges au scrutin de liste.

8. L'article 39 de la déclaration constitutionnelle dispose que cet organe doit être composé uniquement de juges, et qu'il est responsable de la supervision des élections et référendums, depuis l'annonce du calendrier électoral jusqu'à la proclamation des résultats. Sa formation et sa composition relèvent de la loi.

9. Le parlement égyptien est bicaméral : il est composé d'une chambre basse, l'Assemblée du peuple (majlis al-cha'b), chargé de voter les lois, et d'une chambre haute, l'Assemblée consultative (majlis al-chûrâ), ne disposant traditionnellement d'aucun pouvoir contraignant, comme son nom l'indique.

10. Par exemple, la décision prise à la dernière minute d'organiser chaque tour du scrutin sur deux journées au lieu d'une seule a contraint ces acteurs à s'organiser dans l'urgence. L'auteur de cet article a ainsi accompagné un juge au marché de 'Ataba à la veille du premier tour, pour acheter le matériel nécessaire à une mise sous scellés des urnes pendant la nuit séparant les deux jours d'ouverture des bureaux de vote!

11. Voir Iman Farag, «Corrompre, fidéliser : Les ressorts "légitimes" de la compétition électorale égyptienne ", Égypte/Monde arabe, vol. 3, n 7, 2011.

12. Voir notamment Lisa Blaydes and Safinaz El Tarouty, "Women's Electoral Participation in Egypt: The Implications of Gender for Voter Recruitment and Mobilization", The Middle East Journal, 2009, vol. 63, n³.

13. À partir du 19 novembre 2011, des affrontements meurtriers ont opposé plusieurs jours durant les forces de l'ordre à des manifestants réclamant le départ immédiat du CSFA au profit d'un gouvernement de transition animé par des civils. Soldés par une cinquantaine de morts, ces combats de rue n'ont cessé que quelques jours avant l'ouverture du scrutin. Ils se déroulaient pour l'essentiel à l'entrée de la rue Muhammad Mahmûd, qui permet de rejoindre le ministère de l'Intérieur depuis la place Tahrir.

14. Le parti des Frères musulmans.

15. Voir la chronologie en fin de volume.

16. Huwa ibn al-balad. Littéralement : « c'est un enfant du pays ».

17. Le choix de ces trois circonscriptions est en grande partie le fait du hasard et des opportunités: possibilités matérielles d'y demeurer pour une période de deux semaines, présence d'informateurs locaux sur place, etc. Les différences entre ces trois terrains sont donc apparus a posteriori, et n'ont pas joué un rôle déterminant dans leur sélection.

18. Par ailleurs, au troisième jour de la révolution, la veille de l'effondrement de la police, Suez était la seule ville du pays à manifester, alors que le calme était temporairement revenu dans le reste du pays. 
19. Cette circonscription est d'ailleurs la seule où j'ai été amené à travailler en collaboration avec des journalistes de la presse francophone.

20. Pour une brève présentation des partis et candidats à la présidentielle, se reporter au tableau en fin de volume.

21. Voire la définition dans le lexique en fin de volume.

22. C'est la seule circonscription où j'ai pu approcher les futurs vainqueurs, puisque j'ai interrogé le fils de Muhammad Al-Fiqqî, le candidat du Wafd élu député sur le siège fi'ât ("autres catégories » : les candidats qui ne sont ni ouvriers ni paysans) au deuxième tour, et mené un entretien avec le candidat du PLJ, le sheikh Al-Sayyid 'Askar, élu dès le premier tour au siège réservé aux « ouvriers et paysans ».

23. Sur les élections au Muqattam, voir l'article de Gaétan du Roy dans ce numéro.

24. Pour une présentation des différents partis mentionnés ici, se reporter au tableau en fin de volume.

25. Club de sport emblématique de la bourgeoisie cairote.

26. Muhammad 'Urabî et Muhsin Fawzî sont effectivement d'anciens députés du PND. Nihâl 'Ahdî a eu sa carte au parti, sans jamais y exercer de responsabilités ni y briguer de mandat. Quant à Magdî 'Uthmân, même si aucun élément sérieux ne semble le désigner comme fulûl, sa campagne dispendieuse a fait jaser à Suez sur l'origine de sa fortune.

27. Alors président du parti libéral Ghad, Ayman Nûr avait été le principal opposant à Hosni Moubarak lors des premières élections présidentielles pluralistes de l'histoire égyptienne.

28. Elle est arrivée $3^{\mathrm{e}}$ sur le siège fi'ât, battue de peu par le candidat du PLJ 'Amrû Khidr, et celui du Bloc égyptien Muhammad Abû Hâmid.

29. Comme Port-Saïd et Ismaïlia, la ville de Suez a été fondée au moment du percement du canal, et est tournée prioritairement vers le grand large, ce qui l'isole de son arrière-pays. Sur les villes du canal et leur particularisme, lire la thèse de Frédérique Bruyas, De la re-construction régionale à formation d'un territoire du canal de Suez: Acteurs et enjeux, thèse de géographie soutenue en novembre 2002 à l'université François Rabelais de Tour.

30. À peu de chose près, cela ressemble beaucoup à la description faite par Sandrine Gamblin des élections législatives de 1995 à Louxor («Familles, pouvoir et territoires : les élections législatives de 1995 dans une circonscription de Haute-Égypte ", in S. Gamblin (dir.), Contours et détours du politique en Égypte. Les élections législatives de 1995, Paris, L'Harmattan/Cedej, 1997). Les élections organisées sous le régime autoritaire ont ainsi permis de forger tout un répertoire de pratiques, aujourd'hui réinvesties par les acteurs dans un contexte juridico-politique grandement différent.

31. Pour Jacques Berque, la densité du tissu rural du Delta interdit une rupture franche entre les villes et les campagnes dont elles sont issues. Les villes du delta du Nil s'inscrivent ainsi dans un continuum qui va du rural à l'urbain (Jacques Berque, L'Égypte, Impérialisme et Révolution, Paris, NRF Gallimard, 1967). Delphine Pagès-El Karoui nuance et précise ce point de vue : si les petites et moyennes villes du Delta sont composées de "citadins des champs" (c'est-à-dire qu'elles comportent une part importante d'agriculteurs parmi leur population active), ce n'est plus le cas des villes importantes de la région telles que Tanta. Cette dernière n'en a pas moins conservé des liens étroits avec le monde agricole : elle constitue un marché pour les produits de l'agriculture, et ses industries sont principalement liées à l'exploitation des richesses naturelles. Enfin, elle joue un rôle de relais entre le pouvoir central et les campagnes environnantes, pour lesquelles elle constitue également un centre de services (Delphine Pagès-El Karoui, Villes du delta du Nil. Tantâ, Mahalla, Mansûra, Cités de la densité, Paris, CEDEJ/KARTHALA/IISMM, 2008).

32. «Il est économique, pas politique » (Huwa iqtisâdî, mich siyâsî), me dira son fils rencontré dans son local de campagne. J'ai par la suite entendu plusieurs fois cette formule pour le désigner, que mon interlocuteur le déplore ou s'en réjouisse.

33. Ce village aggloméré à Tanta abrite un grand centre universitaire azharite.

34. Hizb Al-Hurriya wal-'adâla huwa hizb Al-Ikhwân al-muslimîn. 
35. Voir infra le rôle historique du sheikh Hâfiz Salâma dans la ville.

36. Il s'agit de Tal'at Al-Khalîl (sur le siège fi'ât) et de Muhammad Abû Masr («ouvriers et paysans »).

37. Janine A. Clark, "Movement Theory and Patron-Clientelism: Islamic Social Institutions and the Middle Class in Egypt, Jordan and Yemen", Comparative Political Studies, vol. 37, 2004.

38. Marie Vannetzel, “"Ils nous ont déjà essayés !" Clientélisme et mobilisation électorale frériste en Égypte ", Politique africaine, vol. 108, 2007.

39. J'ai eu l'occasion d'expérimenter indirectement les attentes suscitées par les Frères en termes de services à la population, lorsqu'un homme m'a interpellé dans une rue de Tanta, disant m'avoir aperçu au local de campagne de Al-Sayyid 'Askar (ce qui était exact). L'homme avait perdu une jambe et avait été soigné à l'hôpital Tîba. Après s'être excusé de me demander cela, il m'a dit qu'il avait besoin d'argent pour nourrir sa famille, et qu'il venait de se rendre au service de la zakât et au local du candidat du PLJ, mais que les deux étaient actuellement fermés. Bien loin de mettre en avant ma qualité d'occidental censément fortuné pour me demander de l'aide, il a ainsi insisté sur notre proximité supposée commune avec la confrérie, laissant ainsi entendre qu'un geste de ma part relèverait de la nature de la relation que cette dernière a noué avec ses électeurs. Lié d'une manière ou d'une autre aux Frères musulmans, j'étais censé, moi aussi, « faire le bien ".

40. Madâris al-jîl al-muslim.

41. Si tous les partis et candidats affichaient leur matériel de campagne dans les grands centres urbains, et même à l'entrée des gros bourgs de Gharbiyya, leurs traces disparaissaient progressivement à mesure que l'on s'enfonçait dans les zones les plus rurales, laissant les salafistes occuper seuls ce terrain avec les affiches appelant à voter pour le parti Nûr et ses candidats.

42. Al-Masrî Al-Yawm, 4 janvier 2012.

43. Binâ' wa-Tanmiya. Allié aux deux partis salafistes Nûr et Asâla, ce parti est issu des Gama'ât islâmiyya, mouvement islamiste qui avait mené une lutte armée contre le régime jusqu'au milieu des années 1990. Ses membres ont par la suite renoncé à l'usage de la violence durant leurs années de prison, et se sont ralliés à l'idée de mener un combat politique en adoptant la forme partisane.

44. À l'exception d'un candidat présent sur la liste du Wafd, aucun de mes enquêtés n'a cru bon d'insister, au cours de nos entretiens, sur les problèmes de la paysannerie. Les thèmes les plus évoqués par les différents candidats étaient la question ouvrière, la santé et l'éducation, ainsi que les enjeux nationaux (place de la religion dans la Constitution, défense des libertés publiques et individuelles, lutte contre la corruption, etc.)

45. Néanmoins, la campagne nationale dans les médias, en grande partie financée par la fortune de Sâwîris, tendait à assimiler le Bloc dans son ensemble au seul parti des Égyptiens libres.

46. À Suez, le Bloc égyptien n'a pas présenté de candidats individuels, laissant ainsi le champ libre à l'ancien député 'Abd Al-Hamîd Kamâl, membre du Tagammu'.

47. Il lui a notamment été reproché une atteinte à la religion musulmane après qu'il a publié sur Twitter, en juin 2011, un dessin représentant Mickey et Minnie Mouse vêtus à la mode salafiste. Malgré ses excuses, il a été poursuivi en justice par un avocat membre du parti Nûr, avant d'être finalement acquitté en mars 2012.

48. Le terme Wasat signifie "centre ». Dans le vocabulaire islamique, il est lié aux notions de justice ('adl), et de modération (itidâl), formées sur la même racine ( $c f$. C. Steuer, «S'approprier un nom pour occuper un espace : Le parti du centre en Égypte ", Mots. Les langages du politique, $\mathrm{n}^{\circ}$ 101, 2013).

49. Respectivement hizb Al-Muhâfizîn et hizb Al-Hurriya. Ces deux partis ont - avec d'autres servis de véhicules aux anciens du PND les plus compromis avec l'ancien régime. 
50. Fondé par la fraction révolutionnaire des jeunes Frères musulmans, en désaccord avec l'attitude prudente de l'organisation-mère à l'égard du régime militaire.

51. Takâtul chabâb Al-Suwîs, « La coalition des jeunes de Suez ».

52. «Au nom de Dieu, Dieu est le plus grand... »

53. Plaçant la filiation divine du Christ au cœur de leur foi, les chrétiens ne peuvent bien évidemment adhérer au contenu de ce verset.

54. L'expression est de Myriam Catusse, «Économie des élections au Maroc », Maghreb-Machrek, $\mathrm{n}^{\circ} 168,2000$.

55. Sur l'affrontement entre le candidat islamiste et ses adversaires sur les plateaux de télévision au cours de la présidentielle, voir l'article de Omneya Nour Eddin Khalifa dans ce numéro.

56. Dans ces clips, le PLJ se présentait à la fois comme le produit de la révolution de 2011, et comme l'héritier de l'histoire longue des Frères musulmans, enfin à portée du pouvoir après des décennies de persécutions. Le parti Nûr avait de son côté réalisé un clip musical, sur fond de nachîd chantant les louanges du parti, qui a eu un grand succès auprès des électeurs. Le PLJ est allé jusqu'à produire un morceau de rap à sa gloire, avec un succès bien plus mitigé.

57. Voir à ce sujet l'article de Giedre Sabaseviciute dans le présent numéro, ainsi que Samer Soliman, 2012, "Les nouvelles forces "civiles" égyptiennes face au défi électoral », Confluences Méditerranée, vol. 82, p. 161-169.

\section{RÉSUMÉS}

Cet article d'ethnographie électorale se base sur une comparaison effectuée entre trois circonscriptions égyptiennes élisant leurs représentants à l'Assemblée du peuple (Qasr Al-Nîl, Suez et la première circonscription de Gharbiya) pour mettre en lumière l'influence de deux variables exogènes sur la stratégie locale des organisations partisanes: le degré d'incertitude pesant sur l'élection, et l'importance relative des différentes circonscriptions dans les médias nationaux.

This article of electoral ethnography rely on a comparison between three Egyptian electoral districts during the 2011-2012 parliamentary elections (Qasr Al-Nîl, Suez and Gharbiya). It emphases the influence of two external factors explaining the local strategy of the political organizations : the level of uncertainty and the relative weight of the district within the national medias.

\section{INDEX}

Mots-clés : partis politiques, niveau local, circonscriptions électorales, incertitude, médias nationaux

Keywords : political parties, local level, electoral districts, uncertainty, national medias 


\section{AUTEUR}

\section{CLÉMENT STEUER}

Clément Steuer est politiste, chercheur associé au CEDEJ et membre du Cercle des chercheurs sur le Moyen-Orient (CCMO). Il travaille actuellement à l'Institut oriental de l'Académie des sciences de République tchèque. Il a également été jeune docteur du laboratoire Triangle, et a été soutenu par une bourse de la région Rhône-Alpes pour ses recherches sur les élections égyptiennes. Il a notamment publié en 2012 Le Wasat sous Moubarak aux éditions de la Fondation Varenne.

Clément Steuer is a political scientist, associate researcher at the CEDEJ, and member of the Research Union on the Middle East. He is currently employed by the Oriental Institute of the Academy of Sciences of the Czech Republic. In addition, as a young academic of the Triangle laboratory, he was being supported by a grant from the "Région Rhône-Alpes" in order for him to undertake research on the Egyptian elections. His monograph, Le Wasat sous Moubarak, was published by the Fondation Varenne publishing house in 2012. 